\title{
Impact of Gleason score of the tumor at the positive surgical margin as a prognostic factor
}

\author{
HIROFUMI KUROSE ${ }^{1,2}$, KOSUKE UEDA ${ }^{1}$, NAOYUKI OGASAWARA ${ }^{1}$, KATSUAKI CHIKUI ${ }^{1}$, \\ MAKOTO NAKIRI $^{1}$, KIYOAKI NISHIHARA ${ }^{1}$, MITSUNORI MATSUO ${ }^{1}$, SHIGETAKA SUEKANE ${ }^{1}$, \\ HIRONORI KUSANO $^{3}$, JUN AKIBA ${ }^{3}$, HIROHISA YANO ${ }^{3}$ and TSUKASA IGAWA ${ }^{1}$ \\ ${ }^{1}$ Department of Urology, Kurume University School of Medicine, Kurume, Fukuoka 830-0011; \\ ${ }^{2}$ Department of Urology, Chikugo City Hospital, Chikugo, Fukuoka 833-0041; \\ ${ }^{3}$ Department of Pathology, Kurume University School of Medicine, Kurume, Fukuoka 830-0011, Japan
}

Received September 26, 2020; Accepted October 27, 2021

DOI: $10.3892 / \mathrm{mco} .2022 .2515$

\begin{abstract}
Although numerous studies have reported that a positive surgical margin (PSM) is the most important predictive factor for biochemical recurrence (BCR) of prostate cancer (PCa), only a small number of studies have evaluated the predictive value of the Gleason score (GS) of the tumor at the margin in radical prostatectomy (RP). The present study aimed to investigate the preoperative factors that predict PSM and the significant predictive factors for BCR in cases with PSM. In addition, it was examined whether documenting the GS of the tumor at the margin in pathological reports is useful as a predictive factor for BCR. Data of 241 patients with PCa who underwent RP at Kurume University Hospital (Kurume, Japan) between January 2007 and December 2011 were retrospectively reviewed. The median follow-up period was 72 months and 122 patients had at least one PSM. The time to BCR was significantly shorter in patients with PSM than in those with a negative surgical margin. Multivariate analysis demonstrated that $>10 \mathrm{ng} / \mathrm{ml}$ prostate-specific antigen at diagnosis $(\mathrm{P}=0.024)$ and $>25 \%$ positive core at biopsy $(\mathrm{P}=0.041)$ were independent prognostic preoperative factors for PSM. The GS of the tumor at the margin was equal, lower and higher than those of the main tumor in 74 (60.7\%), 16 (13.1\%) and 32 (26.2\%) RPs, respectively. The BCR rates were 35.7, 55.1 and $82.1 \%$ in patients whose GS of the tumor at the margin was 6,7 and $8-10$, respectively $(\mathrm{P}=0.0017)$. The GS of the tumor at the PSM $(\mathrm{P}=0.038)$ and anatomic location of the PSM $(\mathrm{P}=0.04)$ were identified as independent prognostic preoperative factors for BCR, whereas the GS of the main tumor and margin length were not. These results suggest that documenting the GS at the margin in pathological reports is useful as a predictive factor for BCR.
\end{abstract}

Correspondence to: Dr Hirofumi Kurose, Department of Urology, Kurume University School of Medicine, 67 Asahi-machi, Kurume, Fukuoka 830-0011, Japan

E-mail: kurose_hirofumi@med.kurume-u.ac.jp

Key words: prostate cancer, positive surgical margin, Gleason score at the margin, biochemical recurrence, radical prostatectomy

\section{Introduction}

Prostate cancer $(\mathrm{PCa})$ is the most common type of solid neoplasm in males (1). When radical prostatectomy (RP) is selected as a treatment for localized $\mathrm{PCa}$, the prognosis is generally favorable (2). However, postoperative biochemical recurrence (BCR) occurs in 16-31\% of patients within 5 years and in 25-53\% within 10 years (3-5). Certain cases develop into castration-resistant $\mathrm{PCa}$ after clinical recurrence, frequently leading to poor outcomes. Thus, BCR is often used to justify the application of salvage therapies, such as endocrine therapy and radiotherapy.

Certain studies have identified various predictive factors for BCR. BCR after prostatectomy has been associated with multiple factors, including the preoperative prostate-specific antigen (PSA) score, positive surgical margins (PSM), the Gleason score (GS) at prostatectomy and pathological staging. Of these, PSM is the most important predictive factor for BCR (6-13). Certain patients with PSM have favorable prognosis after undergoing surgery alone, while others require salvage therapy immediately after surgery and have poor prognosis (14-16). Therefore, patients with PSM are considered to be a highly diverse group and the significance of PSM after RP remains controversial. This finding suggests the requirement for further subclassification of positive margins to identify patients with an elevated risk of BCR. However, only a small number of studies have reported on predictive factors for PSM and BCR in patients with PSM (17). In addition, studies evaluating the usefulness of the GS of the tumor at the margin in RP are currently scarce.

The present study aimed to investigate the preoperative factors that predict PSM and the significant predictive factors for BCR in cases with PSM. In addition, it was examined whether documenting the GS of the tumor at the margin in pathological reports is useful as a predictive factor for BCR.

\section{Patients and methods}

Patients and tissue samples. Patients $(\mathrm{n}=241)$ who underwent prostatectomy at Kurume University Hospital (Kurume, Japan) between January 2007 and December 2011 were 
enrolled in the present study. Most of the surgeries during this period were open procedures. Patients who had received preoperative hormone therapy and/or radiation therapy and those with pathological T stage 0 (pT0) were excluded. As a part of this study, the pathological diagnoses of the patients were re-examined. All patients were pathologically diagnosed with prostatic adenocarcinoma. Histopathological evaluations were performed by three pathologists (HK, KU and HY). Pathological diagnosis was made according to the 2016 World Health Organization Classification of Tumors of the Urinary System and Male Genital Organs (18).

The prostatectomy specimens were pinned to a paraffin block and fixed in $10 \%$ formalin for a minimum of $48 \mathrm{~h}$ and inked on the surface. Paraffin-embedded tissue samples were cut into sections of 4- $\mu \mathrm{m}$ in thickness and examined on coated glass slides. A positive margin was defined as tumor cells abutting the inked surgical margin of the prostate apex, periphery and bladder neck. The GS of the tumor at the PSM was evaluated at the site in contact with the inked margin; when it was difficult to evaluate the GS at the PSM due to heat denaturation, it was evaluated using the continuous non-denaturing site GS (Fig. 1). PSM length was defined as the total length of the tumor in contact with the inked margin. When multiple PSMs were present, the added length of all margins was calculated.

The present study was approved by the Research Ethics Committee of Kurume University (Kurume, Japan) and conformed to the guidelines of the Declaration of Helsinki.

Statistical analysis. The associations between the margin status and GS of the tumor at the margin and clinicopathological characteristics were examined using the $\chi^{2}$ test or Fisher's exact test. Cancer survival analysis was performed using the Kaplan-Meier method, log-rank test and Cox's proportional hazards model. The threshold for statistical significance was set at $\mathrm{P}<0.05$. BCR was defined as an increase in PSA level $(>0.2 \mathrm{ng} / \mathrm{ml})$ after two different measurements at least 3 months apart. For PSA, $10 \mathrm{ng} / \mathrm{ml}$ was used as the cutoff value that was classified as indicative of an intermediate risk in the D'Amico risk classification (7). For the positive core percentage and PSA density, the median was used as the cutoff value. JMP ${ }^{\circledR}$ Pro 14 software (SAS Institute, Inc.) was used to perform all statistical analyses.

\section{Results}

Association between surgical margin and clinicopathological characteristics. Of the 241 patients who had undergone RP, 122 had at least one PSM. The median follow-up period was 72 months. The characteristics of the entire RP cohort, the subset of patients with PSM and the subset with negative surgical margins (NSM) are provided in Table I. Higher PSA level at diagnosis, GS at prostatectomy and pathological $\mathrm{T}$ stage, as well as BCR, were more frequently identified in patients with PSM than in those with NSM (all P<0.05).

Preoperative predictive factors for positive surgical margin in radical prostatectomy. Kaplan-Meier curves demonstrated that the time to BCR was significantly shorter in patients with PSM than in those with NSM (Fig. 2). Univariate and multivariate analyses for preoperative predictive factors for PSM in RP are presented in Table II. Univariate analysis revealed that $>10 \mathrm{ng} / \mathrm{ml}$ PSA at diagnosis, PSA density of $>0.29 \mathrm{ng} / \mathrm{ml} / \mathrm{ml}$, GS at biopsy, clinical T stage, PSA density $>0.29$ and $>25 \%$ positive core at biopsy were significant predictors for PSM. Furthermore, multivariate analysis demonstrated that $>10 \mathrm{ng} / \mathrm{ml}$ PSA at diagnosis and $>25 \%$ positive core at biopsy were independent prognostic preoperative factors for PSM.

Correlation of GS between the tumor at the margin and the main tumor. The GS of the tumor at the margin was 6 in 14 patients $(11.5 \%), 7$ in 69 patients $(56.6 \%$; 35 with GS $3+4$ and 34 with GS 4+3), 8 in 30 patients $(24.6 \%$; all with GS 4+4), 9 in 8 patients (6.5\%; 6 with GS $4+5$ and 2 with GS 5+4) and 10 in 1 patient $(0.8 \%)$. The GS of the tumor at the margin was equal, lower and higher than that of the main tumor in $74(60.7 \%), 16(13.1 \%)$ and $32(26.2 \%) \mathrm{RPs}$, respectively (Table III).

Association of the GS of the positive surgical margin with other variables. The association of the GS of the tumor at the margin and other variables in 122 patients with PSM is presented in Table IV. The GS of the tumor at the margin was highly associated with PSA at diagnosis $(\mathrm{P}=0.048)$, pathological $\mathrm{T}$ stage $(\mathrm{P}=0.0445)$, the $\mathrm{GS}$ of the main tumor $(\mathrm{P}<0.0001)$ and $\mathrm{BCR}$ $(\mathrm{P}=0.0017)$. Within a median follow-up of 72 months, BCR was observed in $75(61.5 \%)$ of the 122 patients. The BCR rates were $35.7,55.1$ and $82.1 \%$ in patients whose GS of the tumor at the margin was 6,7 and 8-10, respectively. The difference in recurrence-free survival among these three groups of patients was significant ( $\mathrm{P}=0.0053$; Fig. 3 ). In addition, the $\mathrm{BCR}$ rates were 52.7, 76.3 and $66.7 \%$ in patients whose anatomic locations at the PSM were apex, periphery and bladder neck, respectively. The difference in recurrence-free survival among the three groups (apex, periphery and bladder neck) of patients was also significant ( $\mathrm{P}=0.0032$; Fig. 4A). Among the 69 patients with GS 7 of the tumor at the margin, no significant difference was observed in recurrence-free survival between those 35 with GS $3+4$ and those 34 with GS 4+3 ( $\mathrm{P}=0.537$; Fig. 4B).

Identification of the GS of the tumor at the margin as a prognostic factor of biochemical recurrence. The results of univariate and multivariate analyses for time to BCR are provided in Table V. Univariate analysis indicated that PSA level at diagnosis, pathological T stage, GS of the main tumor, GS of the tumor at the margin and anatomic location of PSM were strong predictive factors of BCR. On multivariate analysis, the GS of the tumor at the margin $(\mathrm{P}=0.038)$ and anatomic location of PSM $(\mathrm{P}=0.040)$ were identified as independent prognostic preoperative factors for $\mathrm{BCR}$, whereas the GS of the main tumor was not $(\mathrm{P}=0.661)$.

\section{Discussion}

To date, several studies have demonstrated the usefulness of the GS of the tumor at the PSM as a predictor of BCR. Cao et al (17) indicated that both the GS of the main tumor and that of the tumor at the margin were predictors of BCR. However it was previously suggested that there was a difference between the two factors (17). In the present study, it was demonstrated that the GS of the main tumor is not a prognostic 
Table I. Association between surgical margin and clinicopathological characteristics.

\begin{tabular}{|c|c|c|c|c|}
\hline Parameter & Total $(n=241)$ & $\begin{array}{l}\text { Negative surgical } \\
\text { margin }(n=119)\end{array}$ & $\begin{array}{l}\text { Positive surgical } \\
\text { margin }(n=112)\end{array}$ & P-value \\
\hline Age at diagnosis, years & $67(50-77)$ & $67(53-77)$ & $67(50-76)$ & 0.697 \\
\hline \multicolumn{5}{|l|}{ PSA level at diagnosis, $\mathrm{ng} / \mathrm{ml}$} \\
\hline Total & $7.90(2.13-62.34)$ & $6.44(2.13-62.34)$ & $9.42(3.68-52.65)$ & 0.015 \\
\hline$<10$ & $163(67.6)$ & $95(79.8)$ & $68(55.7)$ & 0.011 \\
\hline$\geq 10$ & $78(32.4)$ & $24(20.2)$ & $54(44.3)$ & \\
\hline Gleason score at prostatectomy & & & & 0.013 \\
\hline $6 \geq$ & $27(11.2)$ & $20(16.8)$ & $7(5.7)$ & \\
\hline $3+4=7$ & $103(42.8)$ & $49(41.2)$ & $54(44.3)$ & \\
\hline $4+3=7$ & $75(31.1)$ & $38(31.9)$ & $37(30.3)$ & \\
\hline $8 \leq$ & $36(14.9)$ & $12(10.1)$ & $24(19.7)$ & \\
\hline pT stage & & & & $<0.0001$ \\
\hline $\mathrm{T} 2$ & $176(73.0)$ & $100(84.0)$ & $76(62.3)$ & \\
\hline $\mathrm{T} 3 \mathrm{a}$ & $46(19.1)$ & $15(12.6)$ & $31(25.4)$ & \\
\hline $\mathrm{T} 3 \mathrm{~b}$ & $19(7.9)$ & $4(3.4)$ & $15(12.3)$ & \\
\hline Lymphatic invasion & $12(5.0)$ & $4(3.4)$ & $8(6.6)$ & 0.067 \\
\hline Peripheral nerve invasion & $111(46.1)$ & $41(34.5)$ & $70(57.4)$ & 0.081 \\
\hline Biochemical recurrence positive & $120(49.8)$ & $45(37.8)$ & $75(61.5)$ & $<0.0001$ \\
\hline
\end{tabular}

Values are expressed as $\mathrm{n}(\%)$ or the median (range) for age and total PSA. PSA, prostate-specific antigen.

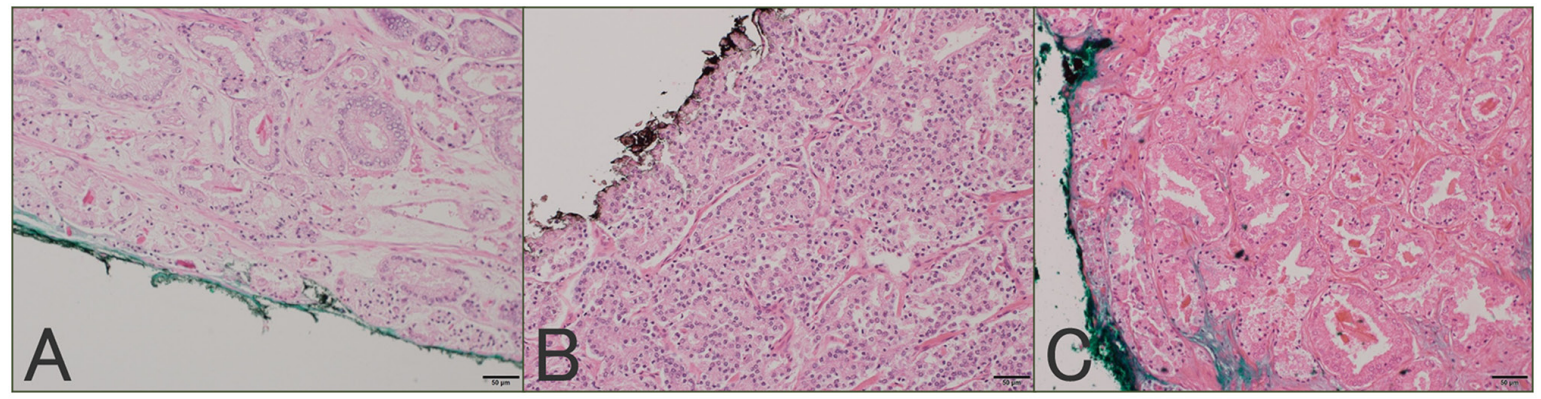

Figure 1. Photomicrographs displaying the GS of the tumor at the margin. (A) GS $3+3=6$; (B) GS 4+4=8, (C) GS $3+3=6$ heat denaturation. The GS of the tumor at the PSM was evaluated at the site in contact with the inked margin in A and B; when it was difficult to evaluate the GS at the PSM due to heat denaturation, it was evaluated using the continuous non-denaturing site GS in C (scale bars, $50 \mu \mathrm{m} ; \mathrm{H} \& \mathrm{E}$ ). GS, Gleason score; PSM, positive surgical margin.

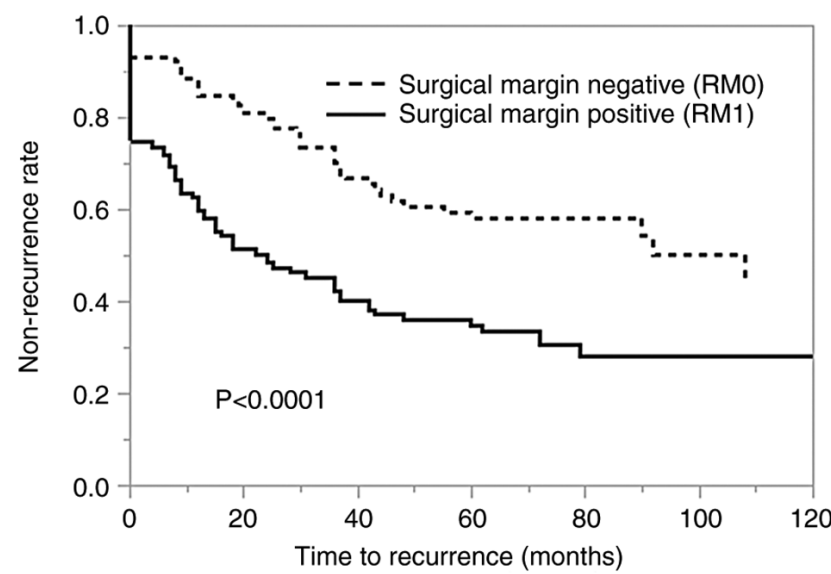

Figure 2. Kaplan-Meier curves for the time to biochemical recurrence compared between patients with positive surgical margin and those with negative surgical margin. RM, resection margin. factor for BCR, whereas that of the tumor at the PSM is an independent prognostic predictor for BCR on multivariate analysis. This result suggested that GS of the tumor at the PSM is a more important factor than that at the main tumor.

PSM is considered the most significant risk factor for BCR after RP. Stephenson et al (19) reported that the PSM was a predictor for BCR based on the result of a multivariate analysis in a large-scale multicenter study involving $>7,000$ individuals. In addition, Wright et al (20) reported that in cases with PSM, the risk of BCR is 3.7 times higher and the risk of PCa-associated death is 1.7 times higher.

Among the predictors of PSM, identifying the preoperative risk factors may prevent BCR through the implementation of more careful surgical manipulation during surgery. Some preoperative factors have been reported previously, as in previous studies, PSA $>10 \mathrm{ng} / \mathrm{ml}$ and a biopsy-positive rate of $>25 \%$ were the factors identified in the present study. 
Table II. Univariate and multivariate analysis for preoperative predictive factor for positive surgical margin in radical prostatectomy.

\begin{tabular}{|c|c|c|c|c|}
\hline \multirow[b]{2}{*}{ Parameter } & \multicolumn{2}{|c|}{ Univariate } & \multicolumn{2}{|c|}{ Multivariate } \\
\hline & OR $(95 \% \mathrm{CI})$ & P-value & OR $(95 \% \mathrm{CI})$ & P-value \\
\hline Age at diagnosis, $>67$ years & $1.05(0.63-1.74)$ & 0.857 & $1.04(0.71-1.52)$ & 0.840 \\
\hline PSA level at diagnosis, $>10 \mathrm{ng} / \mathrm{ml}$ & $3.14(1.77-5.57)$ & $<0.0001$ & $2.28(1.11-3.89)$ & 0.024 \\
\hline $\mathrm{CRP}, \mathrm{mg} / \mathrm{l}$ & $0.76(0.37-1.58)$ & 0.455 & $1.09(0.65-1.81)$ & 0.745 \\
\hline NLR,$>1.58$ & $1.67(0.96-2.91)$ & 0.069 & $1.22(0.79-1.89)$ & 0.368 \\
\hline \multicolumn{5}{|l|}{ Gleason score at biopsy } \\
\hline $6 \geq$ & 1 & 0.0482 & 1 & 0.739 \\
\hline $3+4=7$ & $1.82(0.96-3.44)$ & & $1.16(0.73-1.84)$ & \\
\hline $4+3=7$ & $1.22(0.53-2.83)$ & & $1.21(0.46-1.46)$ & \\
\hline $8 \leq$ & $2.40(1.18-4.88)$ & & $1.31(0.61-1.83)$ & \\
\hline \multicolumn{5}{|l|}{ Clinical T stage } \\
\hline $\mathrm{T} 2$ & 1 & 0.017 & 1 & 0.425 \\
\hline T3a & $2.01(1.20-3.37)$ & & $1.77(0.23-13.5)$ & \\
\hline $\mathrm{T} 3 \mathrm{~b}$ & $4.20(0.42-41.5)$ & & $1.90(0.28-18.6)$ & \\
\hline PSA density $>0.29 \mathrm{ng} / \mathrm{ml} / \mathrm{ml}$ & $2.81(1.67-4.74)$ & $<0.0001$ & $1.48(0.93-2.35)$ & 0.103 \\
\hline Positive core at biopsy, $>25 \%$ & $2.16(1.28-3.65)$ & 0.0035 & $1.42(0.96-2.10)$ & 0.041 \\
\hline
\end{tabular}

PSA, prostate-specific antigen; CRP, C-reactive protein; NLR, neutrophil-to-lymphocyte ratio; OR, odds ratio; CI, confidence interval.

Table III. Correlation of GS between the tumor at the margin and the main tumor.

\begin{tabular}{lrrrrrr}
\hline \multirow{2}{*}{$\begin{array}{l}\text { GS of the } \\
\text { main tumor }\end{array}$} & \multicolumn{5}{c}{ GS of the tumor at the margin } & \\
\cline { 2 - 5 } & 6 & 7 & 8 & 9 & 10 & Total \\
\hline 6 & 7 & 0 & 0 & 0 & 0 & 7 \\
7 & 6 & 66 & 19 & 0 & 0 & 91 \\
8 & 1 & 2 & 11 & 0 & 0 & 14 \\
9 & 0 & 1 & 0 & 8 & 0 & 9 \\
10 & 0 & 0 & 0 & 0 & 1 & 1 \\
Total & 14 & 72 & 30 & 8 & 1 & 122 \\
\hline
\end{tabular}

Values are expressed as the number of patients. GS, Gleason score.

Preston et al (21) reported that among patients with localized PCa with a PSM, the disease-free survival in extraprostatic extention (EPE)+ patients with a negative resection margin was short. The importance of determining the appropriate dissection layer and resection site was confirmed. In the present study, the biochemical non-recurrent survival curves of 122 patients with PSM and 119 with NSM were compared and the incidence of BCR was indicated to be significantly higher in those with PSM.

The frequency of progression to clinical recurrence from BCR without treatment was 34\% (22). In addition, hormone and radiation therapy were performed as salvage therapy for BCR. For radiotherapy in particular, improvement in cancer-specific survival has been reported $(23,24)$. The results of the EORTC22911 trial reported improved clinical progression in

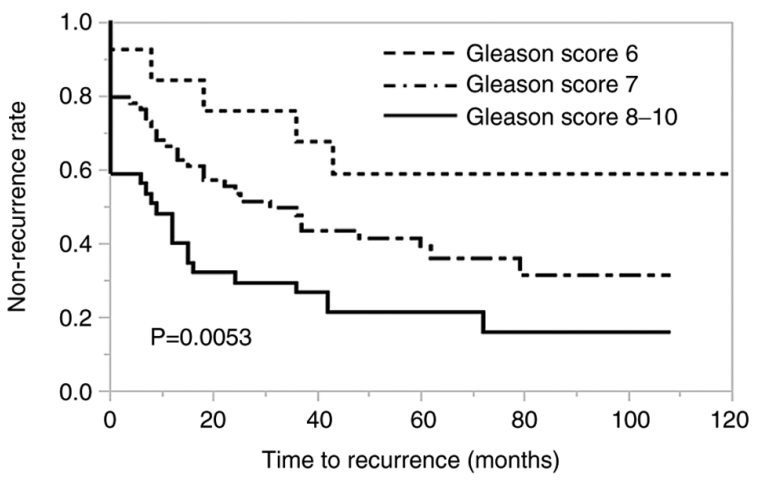

Figure 3. Kaplan-Meier curves for the time to biochemical recurrence stratified by the Gleason score of the tumor at the positive surgical margin.

the postoperative adjuvant radiotherapy group over a follow-up period of $>5$ years after RP (25). Furthermore, to identify the factors related to the effects of postoperative adjuvant radiotherapy, GS, seminal vesicular infiltration, pT stage, EPE and PSM were re-examined using isolated RP specimens of 522 individuals (26). They reported that only PSM was a prognostic factor. With this background, the present study examined risk factors for the purpose of extracting the PSM cases, particularly those that were highly likely to have BCR.

GS is generally used as an indicator of the grade of histopathological malignancy. GS in isolated specimens, in particular, exhibits a more accurate malignancy grade (7). Resnick et al (27) reported that GS in the excised specimen is a risk factor for BCR, even in PSM cases. In recent years, certain studies have reported that the GS of the tumor at the PSM is also a predictor for BCR $(28,29)$. Udo et al $(30)$ reported that the incidence of BCR 
Table IV. Association of the GS of the positive surgical margin with other variables in the cohort $(n=122)$.

\begin{tabular}{|c|c|c|c|c|}
\hline Parameter & $\begin{array}{l}\text { GS of } 6 \text { at the } \\
\text { margin }(n=14)\end{array}$ & $\begin{array}{l}\text { GS of } 7 \text { at the } \\
\text { margin }(n=69)\end{array}$ & $\begin{array}{c}\text { GS of } 8-10 \text { at } \\
\text { the margin }(n=39)\end{array}$ & P-value \\
\hline Age at diagnosis, years & $68(55-76)$ & $67(50-75)$ & $63(53-75)$ & 0.216 \\
\hline PSA level at diagnosis, $\mathrm{ng} / \mathrm{ml}$ & $7.0(4.16-16.5)$ & $9.41(4.05-52.6)$ & $10.4(3.68-50.1)$ & 0.048 \\
\hline Pathological stage & & & & 0.0445 \\
\hline $\mathrm{T} 2$ & 13 & 40 & 23 & \\
\hline $\mathrm{T} 3 \mathrm{a}$ & 1 & 21 & 9 & \\
\hline $\mathrm{T} 3 \mathrm{~b}$ & 0 & 8 & 7 & \\
\hline GS of the main tumor & & & & $<0.0001$ \\
\hline 6 & 7 & 0 & 0 & \\
\hline 7 & 6 & 66 & 19 & \\
\hline 8 & 1 & 3 & 20 & \\
\hline Biochemical recurrence & $5(35.7)$ & $38(55.1)$ & $32(82.1)$ & 0.0017 \\
\hline Median FU time, months & 58 & 69 & 72 & 0.081 \\
\hline
\end{tabular}

Values are expressed as n, n (\%) or the median (range) for age and total PSA. GS, Gleason score; RP, radical prostatectomy; PSA, prostate-specific antigen; FU, follow-up.

Table V. Univariate and multivariate analysis for time to biochemical recurrence.

\begin{tabular}{|c|c|c|c|c|}
\hline \multirow[b]{2}{*}{ Parameter } & \multicolumn{2}{|c|}{ Univariate } & \multicolumn{2}{|c|}{ Multivariate } \\
\hline & $\mathrm{HR}(95 \% \mathrm{CI})$ & P-value & HR $(95 \%$ CI) & P-value \\
\hline Age at diagnosis $>67$ years & $1.04(0.99-1.08)$ & 0.056 & $1.03(0.99-1.09)$ & 0.099 \\
\hline PSA level at diagnosis $>10 \mathrm{ng} / \mathrm{ml}$ & $1.02(1.00-1.04)$ & 0.026 & $2.61(0.93-8.23)$ & 0.063 \\
\hline \multicolumn{5}{|l|}{ Pathological T stage } \\
\hline $\mathrm{T} 2$ & 1 & & 1 & \\
\hline $\mathrm{T} 3 \mathrm{a}$ & $1.36(0.78-2.29)$ & 0.265 & $1.32(0.68-2.56)$ & 0.210 \\
\hline $\mathrm{T} 3 \mathrm{~b}$ & $2.44(1.21-4.55)$ & 0.014 & $1.51(0.63-3.63)$ & 0.130 \\
\hline \multicolumn{5}{|l|}{ GS of the main tumor } \\
\hline 6 & 1 & & 1 & \\
\hline 7 & $3.09(0.96-18.9)$ & 0.137 & $2.22(0.35-2.86)$ & 0.678 \\
\hline $8-10$ & $5.15(1.47-32.5)$ & 0.029 & $1.94(0.49-3.62)$ & 0.661 \\
\hline \multicolumn{5}{|l|}{ GS of the tumor at the PSM } \\
\hline 6 & 1 & & 1 & \\
\hline 7 & $1.92(0.82-5.58)$ & 0.137 & $1.15(0.36-3.98)$ & 0.124 \\
\hline $8-10$ & $3.29(1.39-9.66)$ & 0.005 & $1.78(0.43-5.22)$ & 0.038 \\
\hline Linear length of tumor at the margin, $>3 \mathrm{~mm}$ & $1.31(0.89-1.17)$ & 0.656 & $1.08(0.91-1.25)$ & 0.359 \\
\hline \multicolumn{5}{|l|}{ Anatomic location of the positive margin } \\
\hline Apex & 1 & & 1 & \\
\hline Periphery & $2.12(1.28-3.45)$ & 0.003 & $2.24(1.16-4.30)$ & 0.040 \\
\hline Bladder neck & $1.84(0.79-3.77)$ & 0.118 & $1.19(0.47-3.06)$ & 0.115 \\
\hline
\end{tabular}

PSA, prostate-specific antigen; GS, Gleason score; PSM, positive surgical margin; HR, hazard ratio; CI, confidence interval.

increases when the PSM site contains Gleason grade 4 or higher tissues. In particular, cases with Gleason grade 4 tumors at the PSM have more BCRs than those with only grade 3 tumors (31).

In $\sim 40 \%$ of the present cases, the GS of the tumor at the margin was different from that of the main tumor (lower in $13.1 \%$ and higher in $26.2 \%$ of cases). The multivariate analysis indicated that the GS of the main tumor was not a prognostic factor for $\mathrm{BCR}$, whereas that of the tumor at the PSM was an independent prognostic predictor for BCR. In addition, the GS at the site of a positive margin was significantly associated with the PSA value 

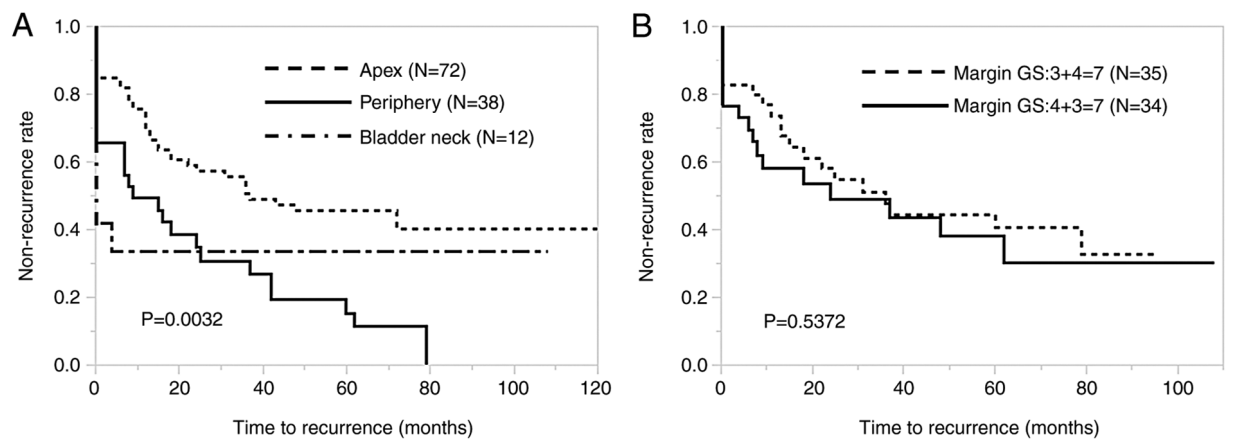

Figure 4. Kaplan-Meier curves for the time to biochemical recurrence stratified by (A) the anatomic location at the margin and (B) between patients with GS $3+4$ and those with GS $4+3$ at the positive surgical margin. GS, Gleason score.

and pT stage. The higher the GS at the positive margin, the earlier the BCR was observed. Evaluation of the GS of the tumor at the margin may be difficult; however, as no significant difference was observed in BCR-free survival between patients whose tumor at the margin had GS 3+4=7 and those whose tumor at the margin had GS $4+3=7$, the GS of the tumor at the positive margin was simply classified into stages 6,7 and 8 or more.

In addition, a positive margin site is more common in the apex of the tumor (32); in the present study, of all patients with a PSM, $\sim 60 \%$ had a positive margin at the apex, which is almost equivalent to the proportion reported in a previous study (32). In the present study of positive sites, BCR occurred significantly earlier in patients with positive margins located laterally than in those with positive margins in the apex and bladder neck sites. PSM located laterally was an independent prognostic predictor of BCR in PSM cases alongside GS at the PSM. This finding demonstrated that documenting the GS of the tumor at the positive margin and at the PSM in the pathology report may accurately identify the presence of BCR.

According to the margin length, Marks et al (33) reported no significant difference between the extent of PSM and BCR. By contrast, Cao et al (34) indicated that the linear length of a PSM was an independent prognostic factor for BCR in stage pT2 cancers. Certain studies have reported a standard linear PSM length of $1 \mathrm{~mm}$, while others have reported a standard length of $3 \mathrm{~mm}$; the impact of the PSM length is still under debate. From the viewpoint of pathologists, measuring the length of multiple positive sites is time-consuming and labor-intensive. Even in the present study, the length of the positive margin site was not a predictor for BCR.

Several limitations of the present study should be acknowledged. First, in this study, PSM was present in 122/241 patients and this proportion is high. The reasons for this may be that about one-third of these cases were at high-risk according to the D'Amico classification and that most of the surgical procedures were open surgeries. Further studies on other surgical procedures (endoscopic/robot-assisted surgery) are required. Furthermore, the length of the tumor was evaluated; however, the width of the tumor was not considered when evaluating the GS of the tumor at the margin in the present study. At our hospital, the width is unified at $3.5 \mathrm{~mm}$ according to Japanese guidelines (35). As the width of all specimens was almost the same, the width was not considered in the present study.

In conclusion, the present study suggested that the GS of the tumor at the PSM in RP is a more significant prognostic factor for BCR than the GS of the main tumor. For a PSM in $\mathrm{RP}$, the GS of the tumor at the margin must be documented, in addition to the anatomic location.

\section{Acknowledgements}

The authors would like to thank Ms. Sachiko Ogasawara (Department of Pathology, Kurume University School of Medicine, Kurume, Japan) for providing technical assistance.

\section{Funding}

No funding was received.

\section{Availability of data and materials}

The datasets used and/or analysis during the current study are available from the corresponding author on reasonable request.

\section{Authors' contributions}

HK, KU, MM, SS and TI designed the study. HK, NO, KC, MN and $\mathrm{KN}$ performed the research. $\mathrm{HK}$, JA and $\mathrm{HY}$ contributed to the pathological analysis. HK analyzed the data and wrote the manuscript. MM, SS, and TI agree to be accountable for all aspects of the work in ensuring that questions related to the accuracy or integrity of any part of the work are appropriately investigated. $\mathrm{HK}$ and KU checked and approved the authenticity of the raw data. All authors read and approved the final manuscript.

\section{Ethics approval and consent to participate}

The present study was approved by the Ethics committee at Kurume University (Kurume, Japan). The Ethics Committee waived the requirement for obtaining written informed consent for the cases as the data of these patients were retrospectively analyzed.

\section{Patient consent for publication}

Not applicable.

\section{Competing interests}

All authors declare that they have no competing interests. 


\section{References}

1. Heidenreich A, Bastian PJ, Bellmunt J, Bolla M, Joniau S, van der Kwast T, Mason M, Matveev V, Wiegel T, Zattoni F, et al: EAU guidelines on prostate cancer. Part 1: Screening, diagnosis, and local treatment with curative intent-update 2013. Eur Urol 65: 124-137, 2014.

2. Nichol AM, Warde P and Bristow RG: Optimal treatment of intermediate-risk prostate carcinoma with radiotherapy: Clinical and translational issues. Cancer 104: 891-905, 2005.

3. Lowrance WT, Eastham JA, Savage C, Maschino AC, Laudone VP, Dechet CB, Stephenson RA, Scardino PT and Sandhu JS: Contemporary open and robotic radical prostatectomy practice patterns among urologists in the United States. J Urol 187: 2087-2092, 2012.

4. Hull GW, Rabbani F, Abbas F, Wheeler TM, Kattan MW and Scardino PT: Cancer control with radical prostatectomy alone in 1,000 consecutive patients. J Urol 167: 528-534, 2002.

5. Stephenson AJ, Kattan MW, Eastham JA, Dotan ZA, Bianco FJ Jr, Lilja $\mathrm{H}$ and Scardino PT: Defining biochemical recurrence of prostate cancer after radical prostatectomy: A proposal for a standardized definition. J Clin Oncol 24: 3973-3978, 2006.

6. D'Amico AV, Chen MH, Roehl KA and Catalona WJ: Preoperative PSA velocity and the risk of death from prostate cancer after radical prostatectomy. N Engl J Med 351: 125-135, 2004.

7. D'Amico AV, Whittington R, Malkowicz SB, Schultz D, Blank K, Broderick GA, Tomaszewski JE, Renshaw AA, Kaplan I, Beard CJ and Wein A: Biochemical outcome after radical prostatectomy, external beam radiation therapy, or interstitial radiation therapy for clinically localized prostate cancer. JAMA 280: 969-974, 1998

8. Horiguchi A, Nakashima J, Horiguchi Y, Nakagawa K, Oya M, Ohigashi T, Marumo K and Murai M: Prediction of extraprostatic cancer by prostate specific antigen density, endorectal MRI, and biopsy Gleason score in clinically localized prostate cancer. Prostate 56: 23-29, 2003.

9. Ohori M, Kattan MW, Koh H, Maru N, Slawin KM, Shariat S, Muramoto M, Reuter VE, Wheeler TM and Scardino PT: Predicting the presence and side of extracapsular extension: A nomogram for staging prostate cancer. J Urol 171: 1844-1849, 2004.

10. Stephenson AJ, Shariat SF, Zelefsky MJ, Kattan MW, Butler EB, Teh BS, Klein EA, Kupelian PA, Roehrborn CG, Pistenmaa DA, et al: Salvage radiotherapy for recurrent prostate cancer after radical prostatectomy. JAMA 291: 1325-1332, 2004.

11. Yossepowitch O, Briganti A, Eastham JA, Epstein J, Graefen M Montironi R and Touijer K: Positive surgical margins after radical prostatectomy: A systematic review and contemporary update. Eur Urol 65: 303-313, 2014.

12. Negishi T, Kuroiwa K, Hori Y, Tomoda T, Uchino H, Tokuda N, Furubayashi N, Nagase K, Iwai H and Nakamura M: Predictive factors of late biochemical recurrence after radical prostatectomy. Jpn J Clin Oncol 47: 233-238, 2017.

13. Blute ML, Bostwick DG, Bergstralh EJ, Slezak JM, Martin SK, Amling CL and Zincke H: Anatomic site-specific positive margins in organ-confined prostate cancer and its impact on outcome after radical prostatectomy. Urology 50: 733-739, 1997.

14. Simon RM, Howard LE, Freedland SJ, Aronson WJ, Terris MK, Kane CJ, Amling CL, Cooperberg MR and Vidal AC: Adverse pathology and undetectable ultrasensitive prostate-specific antigen after radical prostatectomy: Is adjuvant radiation warranted? BJU Int 117: 897-903, 2016.

15. Pettenati C, Neuzillet Y, Radulescu C, Hervé JM, Molinié V and Lebret T: Positive surgical margins after radical prostatectomy: What should we care about? World J Urol 33: 1973-1978, 2015.

16. Simon MA, Kim S and Soloway MS: Prostate specific antigen recurrence rates are low after radical retropubic prostatectomy and positive margins. J Urol 175: 140-145, 2006.

17. Cao D, Kibel AS, Gao F, Tao Y and Humphrey PA: The Gleason score of tumor at the margin in radical prostatectomy is predictive of biochemical recurrence. Am J Surg Pathol 34: 994-1001, 2010.

18. Humphrey PA: WHO clasification of tumors of the prostate, pp138-162, 2016.

19. Stephenson AJ, Wood DP, Kattan MW, Klein EA, Scardino PT, Eastham JA and Carver BS: Location, extent and number of positive surgical margins do not improve accuracy of predicting prostate cancer recurrence after radical prostatectomy. J Urol 182: $1357-1363,2009$.
20. Wright JL, Dalkin BL, True LD, Ellis WJ, Stanford JL, Lange PH and Lin DW: Positive surgical margins at radical prostatectomy predict prostate cancer specific mortality. J Urol 183: 2213-2218, 2010.

21. Preston MA, Carrière M, Raju G, Morash C, Doucette S, Gerridzen RG, Bella AJ, Eastham JA, Scardino PT and Cagiannos I: The prognostic significance of capsular incision into tumor during radical prostatectomy. Eur Urol 59: 613-618, 2011.

22. Pound CR, Partin AW, Eisenberger MA, Chan DW, Pearson JD and Walsh PC: Natural history of progression after PSA elevation following radical prostatectomy. JAMA 281: 1591-1597, 1999.

23. Trock BJ, Han M, Freedland SJ, Humphreys EB, DeWeese TL, Partin AW and Walsh PC: Prostate cancer-specific survival following salvage radiotherapy vs observation in men with biochemical recurrence after radical prostatectomy. JAMA 299: 2760-2769, 2008.

24. Wiegel T, Bottke D, Steiner U, Siegmann A, Golz R, Störkel S, Willich N, Semjonow A, Souchon R, Stöckle M, et al: Phase III postoperative adjuvant radiotherapy after radical prostatectomy compared with radical prostatectomy alone in pT3 prostate cancer with postoperative undetectable prostate-specific antigen: ARO 96-02/AUO AP 09/95. J Clin Oncol 27: 2924-2930, 2009.

25. Bolla M, van Poppel H, Collette L, van Cangh P, Vekemans K, Da Pozzo L, de Reijke TM, Verbaeys A, Bosset JF, van Velthoven R, et al: Postoperative radiotherapy after radical prostatectomy: A randomised controlled trial (EORTC trial 22911). Lancet 366: 572-578, 2005.

26. Van der Kwast TH, Bolla M, Van Poppel H, Van Cangh P, Vekemans K, Da Pozzo L, Bosset JF, Kurth KH, Schröder FH and Collette L; EORTC 22911: Identification of patients with prostate cancer who benefit from immediate postoperative radiotherapy: EORTC 22911. J Clin Oncol 25: 4178-4186, 2007.

27. Resnick MJ, Canter DJ, Guzzo TJ, Magerfleisch L, Tomaszewski JE, Brucker BM, Bergey MR, Sonnad SS, Wein AJ and Malkowicz SB: Defining pathological variables to predict biochemical failure in patients with positive surgical margins at radical prostatectomy: Implications for adjuvant radiotherapy. BJU Int 105: 1377-1380, 2010.

28. Chapin BF, Nguyen JN, Achim MF, Navai N, Williams SB, Prokhorova IN, Wang X, Tapia EM, Davis JW and Troncoso P: Positive margin length and highest Gleason grade of tumor at the margin predict for biochemical recurrence after radical prostatectomy in patients with organ-confined prostate cancer. Prostate Cancer Prostatic Dis 21: 221-227, 2018.

29. Preisser F, Coxilha G, Heinze A, Oh S, Chun FK, Sauter G, Pompe RS, Huland H, Graefen M and Tilki D: Impact of positive surgical margin length and Gleason grade at the margin on biochemical recurrence in patients with organ-confined prostate cancer. Prostate 79: 1832-1836, 2019.

30. Udo K, Cronin AM, Carlino LJ, Savage CJ, Maschino AC, Al-Ahmadie HA, Gopalan A, Tickoo SK, Scardino PT, Eastham JA, et al: Prognostic impact of subclassification of radical prostatectomy positive margins by linear extent and Gleason grade. J Urol 189: 1302-1307, 2013.

31. Viers BR, Sukov WR, Gettman MT, Rangel LJ, Bergstralh EJ, Frank I, Tollefson MK, Thompson RH, Boorjian SA and Karnes RJ: Primary Gleason grade 4 at the positive margin is associated with metastasis and death among patients with Gleason 7 prostate cancer undergoing radical prostatectomy. Eur Urol 66: 1116-1124, 2014.

32. Walz J, Joniau S, Chun FK, Isbarn H, Jeldres C, Yossepowitch O, Chao-Yu H, Klein EA, Scardino PT, Reuther A, et al: Pathological results and rates of treatment failure in high-risk prostate cancer patients after radical prostatectomy. BJU Int 107: 765-770, 2011.

33. Marks RA, Koch MO, Lopez-Beltran A, Montironi R, Juliar BE and Cheng L: The relationship between the extent of surgical margin positivity and prostate specific antigen recurrence in radical prostatectomy specimens. Hum Pathol 38: 1207-1211, 2007.

34. Cao D, Humphrey PA, Gao F, Tao Y and Kibel AS: Ability of linear length of positive margin in radical prostatectomy specimens to predict biochemical recurrence. Urology 77: 1409-1414, 2011.

35. Kawai H: Grneral rule for clinical and pathological studies on prostate cancer: 70-71, 2010.

This work is licensed under a Creative Commons Attribution-NonCommercial-NoDerivatives 4.0 International (CC BY-NC-ND 4.0) License. 